\title{
ACEITABILIDADE E QUALIDADE FÍSICO-QUÍMICA DE PAÇOCAS ELABORADAS COM AMÊNDOA DE BARU ${ }^{1}$
}

\author{
Grazielle Gebrim Santos ${ }^{2}$, Mara Reis Silva ${ }^{3}$, Diracy Betânia Cavalcante Lemos Lacerda ${ }^{4}$, \\ Denise Mendes de Oliveira Martins ${ }^{4}$, Rogério de Araújo Almeida ${ }^{4}$
}

\begin{abstract}
ACCEPTABILITY AND PHYSICOCHEMICAL QUALITY

OF A SWEET MADE FROM Dipteryx alata Vog. NUTS

Baru (Dipteryx alata Vog.), a typical fruit from the Brazilian Savannah, is used for producing cereal bars, cookies, and other typical dishes from the Goiás State (Brazil) gastronomy. This study aimed to evaluate the physical and chemical features, as well as acceptability, of paçoca (a typical Brazilian sweet made from peanuts) made from baru nuts. The control was processed by using only peanuts and the tests comprised proportions of peanut and baru nuts of 75:25, 50:50, and 25:75, respectively. The processed sweets were submitted to sensory, physical, and proximate analyses. The roasted baru nuts showed higher fiber and ash contents than the roasted peanut. The percent increase of baru nuts in the paçoca reduced its lipids content, total energetic value, and overall acceptance, and increased its fiber concentration. Its mass, diameter, and thickness were not affected with the partial substitution of peanuts by baru nuts. Paçocas made with $25 \%$ of baru nuts showed the best results for global acceptance and presented the lowest energetic density and the highest total dietary fiber concentration, when compared to the one traditionally made from peanuts.
\end{abstract}

KEY-WORDS: Dipteryx alata Vog.; sensory evaluation; nutritional features.

\section{INTRODUÇÃO}

O Cerrado é caracterizado por uma grande biodiversidade, no entanto, este bioma está entre os ecossistemas mais ameaçados do mundo (Zaidan \& Carreira 2008). Ao longo dos anos, a vegetação nativa do Cerrado tem sido substituída por pastagens e monoculturas, restando apenas fragmentos de vegetação remanescente (Arakaki et al. 2009).

Inúmeras espécies do Cerrado são utilizadas como alimento, para fins medicinais, ou servem para

\section{RESUMO}

O baru (Dipteryx alata Vog.), fruto típico do Cerrado, é utilizado na produção de barras de cereais, biscoitos, licores e outros pratos típicos da gastronomia regional goiana. $\mathrm{O}$ presente estudo objetivou avaliar as características físicas, químicas e a aceitabilidade de paçocas elaboradas com amêndoas de baru. A paçoca controle foi processada com amendoim e as paçocas testes com proporções de amendoim e amêndoa de baru de 75:25, 50:50 e 25:75, respectivamente. As paçocas elaboradas foram submetidas a análises sensorial, física e da composição centesimal. A amêndoa de baru torrada apresentou maior teor de fibras e cinzas, quando comparada ao amendoim torrado. $\mathrm{O}$ aumento do percentual de amêndoa de baru nas paçocas reduziu o teor de lipídios, o valor energético total e a aceitação global e elevou a concentração de fibras. A massa, diâmetro e espessura das paçocas não se alteraram, com a substituição parcial de amendoim por amêndoa de baru. Paçocas com $25 \%$ de amêndoa de baru tiveram o melhor desempenho, com relação à aceitação global, e apresentaram a menor densidade energética e maior concentração de fibra alimentar total, em comparação à paçoca tradicionalmente elaborada com amendoim.

PALAVRAS-CHAVE: Dipteryx alata Vog.; avaliação sensorial; características nutricionais.

a produção de peças de artesanato. A valorização de espécies nativas pode ser incentivada por meio da pesquisa de suas potencialidades e manejo adequado, contribuindo, assim, para agregar valores rentáveis aos frutos nativos e para a preservação do bioma (Aquino et al. 2007).

O barueiro (Dipteryx alata Vog.) é uma leguminosa arbórea, cujo fruto fornece polpa e amêndoa (semente) comestíveis (Vera \& Souza 2009). Pode ser encontrado na área contínua do domínio Cerrado brasileiro, ocorrendo, com maior frequência, nos Cerradões

1. Trabalho recebido em jun./2011 e aceito para publicação em maio/2012 ( ${ }^{\circ}$ registro: PAT 14646).

2. Anhanguera Educacional, Faculdade de Nutrição Experimental, Anápolis, GO, Brasil.E-mail: grazinutrirte@gmail.com.

3. Universidade Federal de Goiás, Faculdade de Nutrição, Goiânia, GO, Brasil.E-mail: marareis@fanut.ufg.br.

4. Universidade Federal de Goiás, Escola de Agronomia e Engenharia de Alimentos, Goiânia, GO, Brasil.

E-mails: dira.betania@gmail.com,mepidemio@gmail.com,rogerioufg@gmail.com. 
e Matas Secas dos Estados do Tocantins, Goiás, Mato Grosso e Mato Grosso do Sul (Arakaki et al. 2009).

A utilização do baru, de forma sustentável, está sendo intensificada por meio de diversas associações de agricultores familiares, organizações comunitárias regionais e cooperativas agroextrativistas (Nepomuceno 2006). O uso da amêndoa de baru, para fins comerciais, tem sido valorizado em Goiás, especialmente nas cidades de Pirenópolis e Alto Paraíso (Ribeiro et al. 2008).

Atualmente, o fruto é utilizado na produção de barras de cereais, pães, biscoitos, licores, extração de óleo e ainda serve como fonte de inspiração para a gastronomia. Além disto, existe a possibilidade de uso do barueiro em áreas a serem recuperadas, tais como nascentes e margens de rios e córregos, pois pode favorecer a conservação e a manutenção de outras espécies associadas (Sano et al. 2004).

A amêndoa de baru destaca-se por seu elevado teor de proteínas, fibra insolúvel, potássio, magnésio e fósforo (Takemoto et al. 2001). O óleo extraído é composto, principalmente, por mais de $75 \%$ de ácidos graxos insaturados (Vera \& Souza 2009).

Quando torrada, a amêndoa tem características sensoriais semelhantes às do amendoim, apresentando, desta forma, grande potencial para substituí-lo em preparações convencionais, tais como paçocas doces (Togashi \& Sgarbieri 1995, Almeida 1998).

A Organização Mundial da Saúde e o Conselho Nacional de Segurança Alimentar e Nutricional (Consea 2004, WHO 2004) recomendam a inclusão de produtos regionais, a exemplo do baru, na alimentação habitual dos indivíduos, para auxiliar na promoção da saúde.

O aproveitamento de espécies nativas com elevado potencial nutritivo e funcional pode ser uma alternativa ao desenvolvimento social e econômico das comunidades locais. Assim, este trabalho teve por objetivo avaliar as características físicas, químicas e sensoriais de paçocas elaboradas com amêndoas do barueiro, em substituição ao amendoim, em diferentes proporções.

\section{MATERIAL E MÉTODOS}

As amêndoas de baru foram extraídas de frutos obtidos na região rural do Estado de Goiás e os demais ingredientes (fubá de milho, sal, amendoim, leite, fubá de arroz, açúcar refinado, açúcar mascavo e rapadura) foram adquiridos no comércio local da cidade de Goiânia.

As amêndoas de baru e o amendoim foram torrados separadamente, em forno elétrico, à temperatura de $140^{\circ} \mathrm{C}$, durante 30 minutos. Após a torrefação, a película (casca) foi retirada manualmente, quando as amêndoas e o amendoim atingiram temperatura ambiente. A seguir, procedeu-se à trituração em multiprocessador doméstico Wallita Master, com a peça faca, por cerca de 2 minutos, para a obtenção de uma farinha fina, a qual foi passada em peneira de tamis 60 mesh, para uniformidade do tamanho dos grânulos.

A fórmula básica de paçoca descrita por Castelo Branco \& Vianni (1989), com modificações, foi utilizada para elaborar produtos com proporções crescentes de amêndoas de baru. As formulações de paçoca foram testadas com substituição do amendoim por amêndoa de baru nas proporções de 0\% (Paçoca controle - PC), 25\%, 50\% e 75\% (Tabela 1).

O preparo das formulações foi realizado com a homogeneização de todos os ingredientes sólidos em batedeira semi-industrial Kitchen Aid, modelo KEA30, por cerca de 1 minuto, na velocidade 2 (76 rpm), e posterior adição de leite, para obtenção

Tabela 1. Formulações das paçocas com diferentes níveis de substituição de amendoim por amêndoa de baru (Goiânia, GO, 2010).

\begin{tabular}{lrrrr}
\hline \multicolumn{1}{c}{ Ingredientes } & \multicolumn{3}{c}{ Formulações de paçoca ${ }^{1}(\mathrm{~g})$} \\
\cline { 2 - 5 } & $\mathrm{PC}$ & $\mathrm{P} 25$ & $\mathrm{P} 50$ & $\mathrm{P} 75$ \\
\hline Amêndoas de baru torradas e trituradas & - & 103,0 & 205,0 & 306,1 \\
Amendoim torrado e triturado & 411,9 & 308,9 & 205,0 & 102,0 \\
Fubá de arroz torrado & 228,8 & 228,8 & 227,8 & 226,8 \\
Açúcar refinado & 228,8 & 228,8 & 227,8 & 226,8 \\
Leite integral líquido & 128,1 & 128,1 & 132,1 & 136,1 \\
Sal & 2,3 & 2,3 & 2,3 & 2,3 \\
\hline Total $(\mathrm{g})$ & $1.000,0$ & $1.000,0$ & $1.000,0$ & $1.000,0$ \\
\hline
\end{tabular}

${ }^{1}$ PC: formulação controle (100\% de amendoim); P25: formulação com substituição de 25\% do amendoim por amêndoa de baru; P50: formulação com substituição de $50 \%$ do amendoim por amêndoa de baru; P75: formulação com substituição de $75 \%$ do amendoim por amêndoa de baru. 
de uma massa úmida, utilizando-se velocidade 4 (112 rpm), durante 1 minuto. A massa obtida foi prensada em equipamento manual, construído para a produção simultânea de quatro paçocas. As paçocas foram prensadas com o mesmo volume de massa, para todas as formulações, medido em recipiente padronizado (béquer de $100 \mathrm{~mL}$ nivelado). Após a moldagem na prensa, as paçocas foram desenformadas, embaladas com filme plástico (PVC) e armazenadas em sacos de polipropileno, ao abrigo de luz e em temperatura ambiente, até a análise sensorial e análises físicas. Para as análises químicas, as paçocas foram armazenadas em freezer, $\mathrm{a}-18^{\circ} \mathrm{C}$.

A aceitação das paçocas elaboradas foi avaliada por meio de teste afetivo, em laboratório. Participaram do teste 40 provadores, entre alunos e servidores adultos da Universidade Federal de Goiás, de ambos os sexos. A aceitação global (sabor, odor e textura) foi avaliada de forma monádica, em cabines individuais com luz vermelha. Cerca de $30 \mathrm{~g}$ de cada amostra foram servidos em pratos descartáveis, codificados com três dígitos. Foi utilizada escala hedônica estruturada de nove pontos, com os extremos 9 ("gostei muitíssimo") e 1 ("desgostei muitíssimo") (Stone \& Sidel 1985). A aparência de cada produto foi julgada de forma casualizada, apresentando-se as amostras codificadas com números de três dígitos, iluminadas por luz natural. Os provadores também utilizaram a escala hedônica estruturada de nove pontos para avaliar a aparência das paçocas.

As análises físicas e químicas das amêndoas de baru, amendoim e das formulações de paçoca foram realizadas em três repetições por amostra. A análise de proteína bruta foi efetuada conforme o método de Kjeldahl (AOAC 1990), os lipídios totais foram extraídos pela técnica de Bligh \& Dyer (1959) e estimados por gravimetria, a fibra alimentar total foi determinada de acordo com Prosky et al. (1988) e os teores de cinzas por incineração em mulfla, a $550^{\circ} \mathrm{C}$, até obtenção de massa constante (AOAC 1990), e a umidade por secagem em estufa, a $105^{\circ} \mathrm{C}$, até massa constante (IAL 2005). Os carboidratos foram determinados por diferença entre $100 \mathrm{~g}$ do alimento e a soma total dos valores encontrados para umidade, proteína, lipídios, fibra alimentar total e cinzas. As paçocas foram submetidas a análises físicas, para determinação de espessura e diâmetro, com o auxílio de paquímetro.

Para o valor energético total das preparações, foram usados os fatores de conversão descritos por
Atwater (4 $\mathrm{kcal} \mathrm{g}^{-1}$ para carboidratos e proteínas e $9 \mathrm{kcal} \mathrm{g}^{-1}$ para lipídios) (Merril \& Watt 1973).

Foi utilizado o delineamento inteiramente casualizado, com quatro tratamentos e três repetições. Os dados das análises físicas, químicas, aceitação global e aparência foram avaliados por meio de análise de regressão, com exceção dos resultados da composição química do amendoim e amêndoa de baru, que foram analisados com o auxílio do teste t. Os cálculos estatísticos foram feitos utilizando-se o programa STATISTICA 7.0 (Statsoft 2007).

\section{RESULTADOS E DISCUSSÃO}

$\mathrm{O}$ amendoim torrado triturado apresentou teores mais elevados de proteínas, lipídios e valor energético total, quando comparados aos valores observados em amêndoas de baru torradas e trituradas. Por outro lado, os valores de umidade, fibra alimentar total e cinzas foram superiores para a amêndoa de baru torrada (Tabela 2). Estes resultados favorecem a utilização de amêndoa de baru, em comparação ao amendoim, em preparações doces, pois os menores teores de lipídios e o dobro de concentração de fibras na amêndoa podem reduzir o valor energético e potencializar o efeito funcional da fibra no alimento elaborado.

Para o amendoim torrado nas mesmas condições $\left(140^{\circ} \mathrm{C} / 30 \mathrm{~min}\right.$.), foram observados, no estudo de Fernandes et al. (2010), valores inferiores de umidade, teores superiores de lipídios e de fibra alimentar total e valores similares de proteínas e cinzas.

Ao avaliarem sementes de oleaginosas comestíveis, Venkatachalam \& Sathe (2006) encontraram teores similares de lipídios em amendoim (Tabela 2). Fernandes et al. (2010) avaliaram a composição de amêndoas de baru de seis árvores nativas do Estado de Goiás, torradas nas mesmas condições $\left(140^{\circ} \mathrm{C} / 30 \mathrm{~min}\right.$.), e obtiveram teores de umidade, proteínas, lipídios e fibra alimentar próximos aos encontrados no presente trabalho.

Os valores da composição centesimal da amêndoa de baru também foram semelhantes aos relatados por Takemoto et al. (2001). Sousa et al. (2011) obtiveram concentrações mais elevadas de cálcio, ferro e potássio e mais baixas de sódio, para amêndoa de baru, em comparação às do amendoim. Os resultados para cinzas também foram superiores para a amêndoa de baru e próximos aos obtidos neste estudo. 
Tabela 2. Composição centesimal (g $\left.100 \mathrm{~g}^{-1}\right)$ e valor energético total do amendoim e amêndoa de baru torrados (Goiânia, GO, 2010) e dados da literatura referentes à amêndoa de baru e ao amendoim.

\begin{tabular}{|c|c|c|c|c|c|c|c|}
\hline \multirow{2}{*}{ Características } & \multicolumn{2}{|c|}{$\begin{array}{l}\text { Composição centesimal } \\
\qquad\left(\mathrm{g} 100 \mathrm{~g}^{-1}\right)^{1}\end{array}$} & \multicolumn{3}{|c|}{$\begin{array}{l}\text { Composição da amêndoa de baru } \\
\qquad\left({\left.\mathrm{g} 100 \mathrm{~g}^{-1}\right)}^{-1}\right.\end{array}$} & \multicolumn{2}{|c|}{$\begin{array}{l}\text { Composição do amendoim } \\
\left({\left.\mathrm{g} 100 \mathrm{~g}^{-1}\right)}\right.\end{array}$} \\
\hline & $\begin{array}{l}\text { Amendoim } \\
\text { torrado }\end{array}$ & $\begin{array}{l}\text { Amêndoa de } \\
\text { baru torrada }\end{array}$ & $\begin{array}{l}\text { Fernandes } \\
\text { et al. }(2010)\end{array}$ & $\begin{array}{l}\text { Takemoto } \\
\text { et al. }(2001)\end{array}$ & $\begin{array}{l}\text { Sousa et } \\
\text { al. }(2011)\end{array}$ & $\begin{array}{l}\text { Fernandes } \\
\text { et al. }(2010)\end{array}$ & $\begin{array}{l}\text { Venkatachalam \& } \\
\text { Sathe }(2006)^{2}\end{array}$ \\
\hline Umidade & $1,41 \pm 0,08$ & $2,47 \pm 0,02 *$ & 3,71 & 6,10 & 3,49 & 2,80 & 7,09 \\
\hline Proteína $(\mathrm{N} x$ 6,25) & $33,26 \pm 0,52$ & $26,53 \pm 1,47^{*}$ & 25,81 & 23,90 & 29,92 & 32,60 & 21,56 \\
\hline Lipídios totais & $42,74 \pm 0,82$ & $40,35 \pm 0,97^{*}$ & 41,97 & 38,20 & 41,95 & 44,50 & 42,88 \\
\hline Carboidratos & $14,91 \pm 0,50$ & $16,98 \pm 2,80$ & 13,61 & 15,80 & 12,25 & 9,56 & - \\
\hline FAT & $5,23 \pm 0,84$ & $10,59 \pm 0,30 *$ & 11,58 & 13,40 & 9,21 & 8,14 & - \\
\hline Cinzas & $2,45 \pm 0,04$ & $3,08 \pm 0,04 *$ & 3,32 & 2,70 & 3,18 & 2,40 & 1,60 \\
\hline $\operatorname{VET}\left(\mathrm{kcal} 100 \mathrm{~g}^{-1}\right)^{3}$ & $577,31 \pm 5,37$ & $537,20 \pm 5,54 *$ & 535,42 & 502,00 & 546,23 & 569,10 & - \\
\hline
\end{tabular}

${ }^{1}$ Os valores constituem médias \pm desvios-padrão de três repetições, exceto fibra alimentar total (FAT), analisada em quatro repetições. * Diferença significativa, em uma mesma linha, pelo teste t, a $5 \% .{ }^{2}$ Os dados referentes a carboidratos, fibra alimentar e valor energético total não estão disponíveis na literatura citada. ${ }^{3}$ VET: valor energético total.

Os escores da aceitação global atribuídos pelos provadores tiveram uma tendência de elevação até a paçoca com $25 \%$ de amêndoa de baru, seguindo redução dos valores para P50 e P75. O efeito linear da percentagem de baru foi significativo para a aceitação global $(\mathrm{p} \leq 0,05)$, com coeficiente de determinação $\left(\mathrm{R}^{2}\right)$ de 0,74 (Figura 1).

Possivelmente, a elevada percentagem de substituição do amendoim pela amêndoa de baru tenha promovido alterações sensoriais da paçoca P50 e P75, em relação à $\mathrm{PC}$ e $\mathrm{P} 25$, reduzindo a aceitação global dos provadores. Entretanto, a média de aceitação global da paçoca P50 foi de 7,35, com $85 \%$ de provadores atribuindo escores acima de seis ("gostei levemente"), enquanto, para P75, a média de aceitação global foi de 6,42. Quanto à aparência, não houve efeito linear ou quadrático significativo $(\mathrm{p} \geq 0,05)$, sendo que os maiores escores foram atribuídos à P25 e P50.

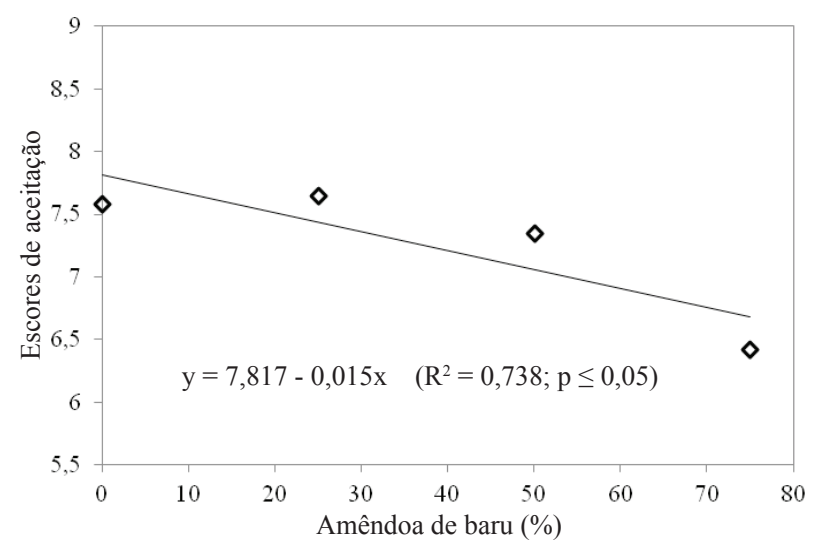

Figura 1. Aceitação global das paçocas, em função do percentual de amêndoa de baru utilizado na elaboração (Goiânia, GO, 2010).
Apesar do consumo disseminado de paçoca de amendoim no Brasil, a literatura científica sobre o assunto é bastante escassa. Wang et al. (1999) pesquisaram paçocas com substituição parcial de amendoim por resíduo do leite de soja e verificaram que o sabor e a textura das paçocas com os menores níveis de substituição (até $10 \%$ de amendoim por resíduo de soja) foram similares ao controle. Os produtos formulados com $15 \%$ e $25 \%$ de substituição diferiram do controle em sabor e textura, porém, a aparência foi similar. Quanto maior a percentagem de substituição do amendoim, menores as notas atribuídas pelos provadores, para aceitação das paçocas elaboradas com resíduo de soja. Estes resultados estão próximos aos observados no presente estudo. Provavelmente, o costume tradicional de uso de amendoim para preparação de paçocas doces tenha interferido na aceitabilidade global atribuída pelos provadores.

A substituição parcial do amendoim por amêndoa de baru nas formulações de paçoca não alteraram as características físicas das paçocas testes, em relação à formulação controle (PC). Para o diâmetro, houve maior uniformidade dos valores, por causa da característica cilíndrica da forma utilizada no processo de prensagem das paçocas (Tabela 3 ). Não foi observado ajuste linear ou quadrático $(\mathrm{p} \geq 0,05)$ do diâmetro, espessura e massa das paçocas, em função do percentual de substituição de amendoim por amêndoa de baru.

A similaridade física das paçocas pode facilitar o processo de embalagem, uma vez que, mesmo com percentuais diferenciados de amendoim e amêndoa de baru, as dimensões do produto não foram alteradas. Neste caso, embalagens com características 
Tabela 3. Características físicas das formulações-controle e com amêndoas de baru (Goiânia, GO, 2010).

\begin{tabular}{lcrrr}
\hline \multirow{2}{*}{ Análises ${ }^{1,2}$} & \multicolumn{5}{c}{ Formulações } \\
\cline { 2 - 5 } & PC & P25 & P50 & P75 \\
\hline Diâmetro (cm) & 3,5 & 3,5 & 3,5 & 3,5 \\
Espessura (cm) & $3,52 \pm 0,09$ & $3,53 \pm 0,11$ & $3,58 \pm 0,09$ & $3,54 \pm 0,12$ \\
Massa (g) & $35,03 \pm 1,50$ & $34,77 \pm 1,86$ & $35,50 \pm 1,40$ & $34,43 \pm 0,95$ \\
\hline
\end{tabular}

${ }^{1}$ Dados apresentados como média \pm desvio-padrão de oito repetições amostra ${ }^{-1} .{ }^{2} \mathrm{PC}$ : formulação controle (100\% de amendoim); P25: formulação com substituição de $25 \%$ do amendoim por amêndoa de baru; P50: formulação com substituição de 50\% do amendoim por amêndoa de baru; P75: formulação com substituição de $75 \%$ do amendoim por amêndoa de baru.

semelhantes podem ser utilizadas para qualquer tipo de paçoca.

A substituição parcial do amendoim por amêndoa de baru, nas formulações de paçoca, reduziu linearmente os teores de lipídios e o valor energético das preparações (Figuras 2 e 3). Contrariamente, os valores de fibra alimentar tiveram efeito linear crescente (Figura 2). O teor de proteínas, carboidratos, cinzas e umidade das paçocas permaneceram relativamente constantes, com pequenas variações, conforme o percentual de amêndoa de baru (Tabela 4).

Apesar de a amêndoa de baru utilizada no presente estudo apresentar teor proteico $20 \%$ inferior ao do amendoim (Tabela 2), a variação da concentração de proteína, com a substituição do amendoim por amêndoa de baru, não foi suficiente para explicar efeitos lineares ou quadráticos. No entanto, a mistura de amendoim e amêndoa de baru, possivelmente, melhora a qualidade da proteína, pois Sousa et al. (2011) analisaram a qualidade nutricional da amêndoa de baru e amendoim e relataram valor de digestibilidade da proteína corrigida pelo escore de aminoácidos (protein digestibility-corrected amino acid score - PDCAAS) mais elevado para amêndoa de baru $(90,70 \%)$, em comparação ao amendoim
(82,54\%). Assim, estes autores sugerem a inclusão da amêndoa de baru na alimentação de indivíduos saudáveis, como fonte de proteína completar, além de cálcio e de ferro, e por causa do seu potencial como alimento funcional.

A substituição de amendoim por amêndoa de baru promoveu aumento no teor de fibra alimentar total da formulação $(p \leq 0,05)$. De acordo com a Portaria

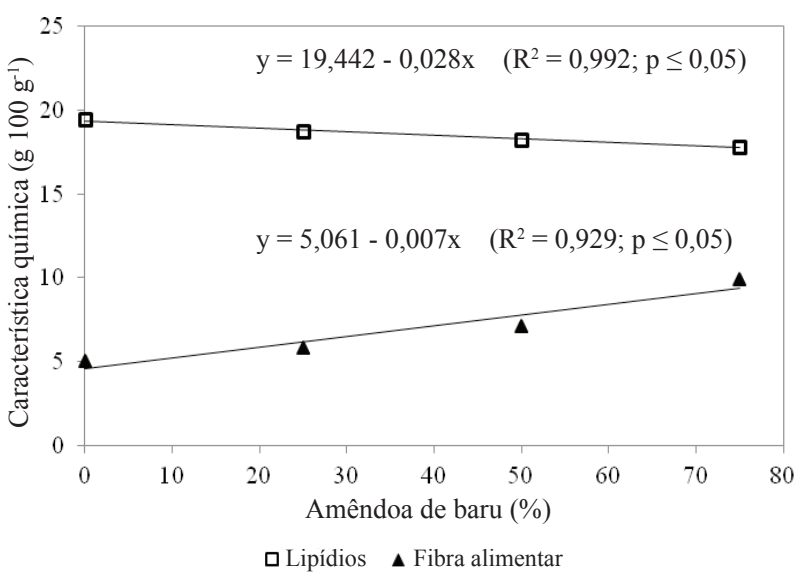

Figura 2. Concentração de lipídios e fibra alimentar nas paçocas, em função do percentual de amêndoas de baru utilizado na sua elaboração (Goiânia, GO, 2010).

Tabela 4. Valor energético e composição centesimal das paçocas, em função do percentual de amêndoa de baru utilizado na sua elaboração (Goiânia, GO, 2010).

\begin{tabular}{|c|c|c|c|c|}
\hline \multirow{2}{*}{$\begin{array}{l}\text { Componente } \\
\left(\mathrm{g} 100 \mathrm{~g}^{-1}\right)^{1,2}\end{array}$} & \multicolumn{4}{|c|}{ Formulações } \\
\hline & $\mathrm{PC}$ & $\mathrm{P} 25$ & P50 & P75 \\
\hline Proteína $(\mathrm{N}$ x 6,25$)$ & $16,72 \pm 0,23$ & $15,81 \pm 0,31$ & $14,27 \pm 0,17$ & $13,53 \pm 0,21$ \\
\hline Lipídios totais & $19,45 \pm 0,32$ & $18,77 \pm 1,37$ & $18,28 \pm 1,04$ & $17,81 \pm 0,14$ \\
\hline Carboidratos & $44,73 \pm 0,86$ & $44,87 \pm 1,23$ & $44,81 \pm 0,93$ & $43,16 \pm 0,70$ \\
\hline Fibra alimentar total & $5,01 \pm 0,90$ & $5,86 \pm 0,19$ & $7,16 \pm 0,06$ & $9,93 \pm 0,21$ \\
\hline Cinzas & $1,35 \pm 0,01$ & $1,35 \pm 0,07$ & $1,48 \pm 0,51$ & $1,53 \pm 0,03$ \\
\hline Umidade & $12,65 \pm 0,22$ & $13,31 \pm 0,08$ & $13,98 \pm 0,06$ & $14,03 \pm 0,72$ \\
\hline Valor energético total $\left(\mathrm{kcal} 100 \mathrm{~g}^{-1}\right)$ & $420,94 \pm 11,94$ & $411,72 \pm 6,30$ & $400,87 \pm 5,36$ & $387,11 \pm 3,58$ \\
\hline
\end{tabular}




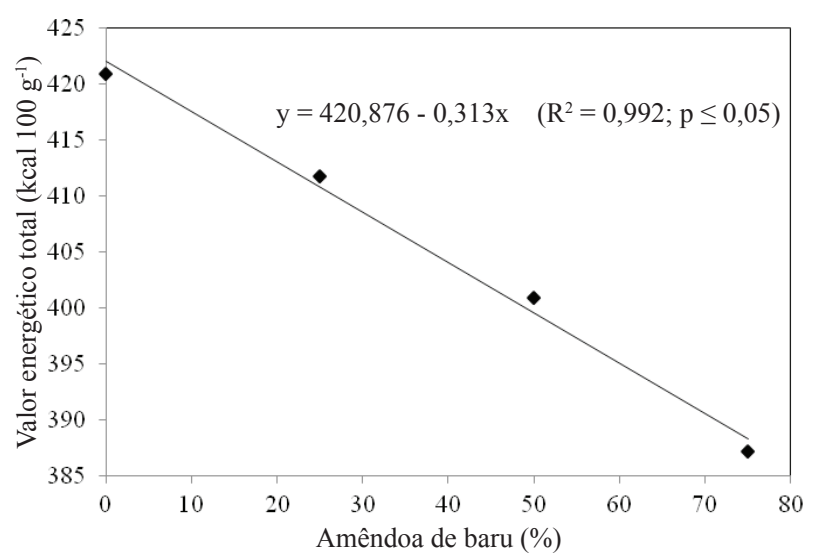

Figura 3. Valor energético total das paçocas, em função do percentual de amêndoas de baru utilizado na sua elaboração (Goiânia, GO, 2010).

n ${ }^{\circ}$ 27/98, da Secretaria de Vigilância Sanitária do Ministério da Saúde (Brasil 1998), alimento fonte e rico em fibra é aquele com teor de $3 \mathrm{~g}$ e $6 \mathrm{~g}$ de fibra alimentar total por $100 \mathrm{~g}$ de alimento sólido, respectivamente. Portanto, P25 pode ser considerada fonte de fibra e as formulações P50 e P75 ricas em fibra (Tabela 4).

A redução proporcional dos valores energéticos das formulações, com o aumento da proporção de amêndoa de baru, pode ser atribuída à diminuição da concentração de lipídios e ao aumento da fibra alimentar, com a substituição do amendoim por amêndoa de baru.

No Brasil, há tendência de redução de déficits nutricionais e aumento da prevalência de sobrepeso e obesidade, em crianças e adolescentes. As causas destas alterações podem estar ligadas a mudanças de hábitos alimentares e estilo de vida (Rinaldi et al. 2008). Dentre outros fatores, a composição, quantidade e qualidade dos alimentos consumidos têm sido relacionadas à obesidade (Triches \& Giugliani 2005, Rinaldi et al. 2008). Portanto, o consumo de alimentos saudáveis e com valor energético mais baixo pode auxiliar na prevenção do excesso de peso e obesidade.

\section{CONCLUSÕES}

1. A substituição do amendoim por amêndoa de baru não alterou as características físicas da paçoca. No entanto, a utilização de amêndoa de baru, como substituto do amendoim, deve ser de, no máximo, $25 \%$, para manter ou melhorar a composição química, sem interferir na aceitação do produto.
2. Paçocas com $50 \%$ e $75 \%$ de substituição de amendoim por amêndoa de baru tiveram melhor desempenho, com relação ao aumento da concentração de fibra alimentar e redução do valor energético, no entanto, foram menos aceitas.

3. O aproveitamento de frutos do Cerrado, como amêndoas de baru, em produtos alimentícios tradicionais, é possível, sem que alterações de qualidade sejam observadas, aumentando, assim, o valor nutritivo do produto e favorecendo a preservação do bioma Cerrado.

\section{REFERÊNCIAS}

ALMEIDA, S. P. Cerrado: aproveitamento alimentar. Brasília, DF: Embrapa-CPAC, 1998.

AQUINO, F. G.; WALTER, B. M. T.; RIBEIRO, J. F. Espécies vegetais de uso múltiplo em reservas legais de Cerrado - Balsas, MA. Revista Brasileira de Biociências, Porto Alegre, v. 5, supl., p. 147-149, 2007.

ARAKAKI, A. H. et al. O baru (Dipteryx alata Vog.) como alternativa de sustentabilidade em área de fragmento florestal do Cerrado, no Mato Grosso do Sul. Interações, Campo Grande, v. 10, n. 1, p. 31-39, 2009.

ASSOCIATION OF OFFICIAL AGRICULTURAL CHEMISTS (AOAC). Official methods of analysis. 15. ed. Washington, D.C.: AOAC, 1990.

BLIGH, E. G.; DYER, W. J. A rapid method of total lipid extraction and purification. Canadian Journal of Biochemistry and Physiology, Toronto, v. 37, n. 8, p. 911917, 1959.

BRASIL. Ministério da Saúde. Secretaria de Vigilância Sanitária. Portaria $\mathrm{n}^{\circ}$ 27, de 13 de janeiro de 1998. Aprova o regulamento técnico referente à informação nutricional complementar. Diário Oficial, Brasília, DF, 16 jan. 1998. Seção 1.

CASTELO BRANCO, N. S. D.; VIANNI, R. Aceitabilidade e valor nutricional de paçocas elaboradas com amendoim, fubá e farinha de soja desengordurada. Ciência e Tecnologia de Alimentos, Campinas, v. 9, n. 1, p. 21-44, 1989.

CONSELHO NACIONAL DE SEGURANÇA ALIMENTAR E NUTRICIONAL (Consea). Relatório final da II conferência nacional de segurança alimentar e nutricional. Olinda: Consea, 2004.

FERNANDES, D. C. et al. Nutritional composition and protein value of the baru (Dipteryx alata Vog.) almond from the Brazilian Savanna. Journal of the Science of Food and Agriculture, London, v. 90, n. 10, p. 1650-1655, 2010. 
INSTITUTO ADOLFO LUTZ (IAL). Métodos fisicoquímicos para análise de alimentos. 4. ed. Brasília, DF: Ministério da Saúde, 2005.

MERRILL, A. L.; WATT, B. K. Energy value of foods: basis and derivation. Washington, DC: United States Department of Agriculture, 1973. (Agriculture handbook, 74).

NEPOMUCENO, D. L. M. G. O extrativismo de baru (Dipteryx alata Vog) em Pirenópolis (GO) e sua sustentabilidade. Dissertação (Mestrado em Ecologia e Produção Sustentável)-Universidade Católica de Goiás, Goiânia, 2006.

PROSKY, L. et al. Determination of insoluble, soluble, and total dietary fiber in foods and foods products: interlaboratory study. Journal of the Association of Official Analytical Chemists, Arlington, v. 71, n. 5, p. 1017-1023, 1988.

RIBEIRO, J. F.; ALMEIDA, S. P.; SANO, S. M. Cerrado: ecologia e flora. Brasília, DF: Embrapa, 2008.

RINALDI, A. E. et al. Contribuições das práticas alimentares e inatividade física para o excesso de peso infantil. Revista Paulista de Pediatria, São Paulo, v. 26, n. 3, p. 271-277, 2008.

SANO, S. M.; RIBEIRO, J. F.; BRITO, M. A. Baru: biologia e uso. Brasília, DF: Embrapa Cerrados, 2004. (Documentos, 116).

SOUSA, A. G. O. et al. Nutritional quality and protein value of exotic almonds and nut from the Brazilian Savanna compared to peanut. Food Research International, Barking, v. 44, n. 7, p. 2319-2325, 2011.

STATSOFT. Statistica 7.0. Tulsa: Stat Soft Inc., 2007.
STONE, H.; SIDEL, J. L. Affective testing. In: STONE, H.; SIDEL, J. L. Sensory evaluation practices. Boca Raton: Academic Press, 1985. p. 227-252.

TAKEMOTO, E. et al. Composição química da semente e do óleo de baru (Dipteryx alata Vog.) nativo do município de Pirenópolis, Estado de Goiás. Revista do Instituto Adolfo Lutz, São Paulo, v. 60, n. 2, p. 113-117, 2001.

TOGASHI, M.; SGARBIERI, V. C. Avaliação nutricional e da proteína do óleo de semente de baru (Dipteryx alata Vog.). Ciência e Tecnologia de Alimentos, Campinas, v. 15, n. 1, p. 66-69, 1995.

TRICHES, R. M.; GIUGLIANI, E. R. J. Obesidade, práticas alimentares e conhecimentos de nutrição em escolares. Revista de Saúde Pública, São Paulo, v. 39, n. 4, p. 541-547, 2005.

VENKATACHALAM, M.; SATHE, S. K. Chemical composition of selected edible nut seeds. Journal of Agricultural and Food Chemistry, Washington, DC, v. 54, n. 13, p. 4705- 4714, 2006.

VERA, R.; SOUZA, E. R. B. Baru. Revista Brasileira de Fruticultura, Jaboticabal, v. 31, n. 1 p. 112-118, 2009.

WANG, S. H.; CABRAL, L. C.; BORGES, G. G. Utilização do resíduo do leite de soja na elaboração de paçoca. Pesquisa Agropecuária Brasileira, Brasília, DF, v. 34, n. 7, p. 1305-1311, 1999.

WORLD HEALTH ORGANIZATION (WHO). Global strategy on diet, physical activity and health. Geneva: WHO, 2004.

ZAIDAN, L. B. P.; CARREIRA, R. C. Seed germination in Cerrado species. Brazilian Journal of Plant Physiology, Piracicaba, v. 20, n. 3, p. 167-181, 2008. 